An International ejournal of Prehospital Care Research, Education, clinical Practice, Policy and Service Delivery

ISSN 1447-4999

\title{
Education
}

\section{FLEXIBLE, FOCUSED TRAINING: KEEPS VOLUNTEER AMBULANCE OFFICERS}

Article No. 990017

\begin{abstract}
Ms Christine Fahey, University Department of Rural Health, Tasmania Professor Judi Walker, University Department of Rural Health, Tasmania Mr. Grant Lennox, Tasmanian Ambulance Services
\end{abstract}

\begin{abstract}
This paper reports the training findings of the Stand Up and Be Counted Project, a study of Australian and New Zealand Volunteer Ambulance Officers (VAO), the first-line response to medical emergencies in rural and remote areas. VAO are a dwindling resource in regional and rural areas with a great need for such services due their isolation from other health services. The study, financed by Emergency Management Australia, aimed to devise strategies to improve the situation. The project surveyed 2,500 VAO from Western Australia, Queensland, Victoria, Tasmania, Northern Territory, South Australia and New Zealand's North and South islands. This research has a wider application for other emergency services as they undergo similar changes and pressures related to training volunteers under the new Australian Quality Training Framework. The new framework has increased the training and accreditation requirements for many volunteers, and anecdotal evidence before the research suggested that too much training was a disincentive for $\mathrm{VAO}$, making it difficult for ambulance services to recruit or retain volunteers. Our research confirmed that training is important for VAO. The polarization in some responses were considered to have three causes: different training systems per jurisdiction; different levels of isolation and other regionalisation factors meant some units were better serviced than others; and individuals had different expectations and capacities. However the study found that as long as VAO are protected from excessive and onerous bureaucratic processes, and provided with quality training, a competency-based training with national standards is not a disincentive. If done well, training will be a strategic recruitment and retention tool by increasing the confidence and sense of achievement VAO feel.
\end{abstract}

Key words: training, volunteers, rural health, ambulance officers

\section{Introduction}

Volunteers have a long history in ambulance services and they still play a vital role in regional and rural areas of Australia and New Zealand. This role has often been taken for granted but as ambulance services, like other emergency 
services, have experienced growing difficulties with recruitment and retention of Volunteer Ambulance Officer (VAO), they have been forced to refocus.

It is important that Australia and New Zealand develop and maintain a skilled rural ambulance workforce as in most rural and remote Australian towns there is total reliance on approximately 7,000 VAO for first-line response to medical emergencies. VAO form an important first link for rural areas in Tasmania, Western Australia, Victoria, South Australia, Northern Territory, Queensland and New Zealand's North and South Islands. There are many reasons why those living in rural and remote areas have poorer health indicators than those living in metropolitan areas, but with a rate of avoidable deaths (particularly from injury, asthma, and suicide), which is $40 \%$ greater than in urban areas ${ }^{1}$ it is vital that ambulance services be maintained.

A compounding factor is that Australian emergency services are incorporating new nationally accredited competency standards for training volunteers. The aim is to increase the standards of training to ensure organisations meet a duty of care ${ }^{2}$, but the accompanying increase in training and accreditation requirements could be a deterrent to potential volunteers ${ }^{34}$. Unfortunately, lack of specific information about factors that boost recruitment and retention of rural ambulance officers makes it difficult to estimate the impact the new training standards will have on VAO, and generally plan strategically to sustain the volunteer workforce. ${ }^{3-7}$. What is certain is that ambulance services cannot allow the new training qualifications to increase VAO exit rates and deter recruitment.

To address this rural health workforce problem in Australia and New Zealand we gathered data from volunteer ambulance officers in Australia and New Zealand regarding, recruitment, retention, training and support. This study was part of the Stand Up and Be Counted Project financed by Emergency Management Australia to devise strategies to improve the situation ${ }^{8}$. We surveyed VAO in all jurisdictions. Here we report our findings on the substantial potential of training as a strategic recruitment and retention tool. An earlier paper reports the training implications from the Tasmanian pilot study, with some overlap in findings ${ }^{9}$.

\section{Methods}

A questionnaire was developed with advice from an advisory committee of major stakeholders, and minor changes were made after piloting in Tasmania. We included items on VAO length of service, age groups, sex, motivations, recruitment prompts and training attitudes. The questionnaire was mailed to the entire population of VAO in Tasmania, estimated at 380 at the time of survey, with a $55 \%$ (206) response rate. A year later a random sample of 2,200 VAO from Western Australia, Queensland, Victoria, Northern Territory, South Australia and New Zealand's North and South islands were surveyed, with a response rate of $38 \%$.

After coding the open-ended items on the questionnaire we processed the data using SPPS software. Responses were analysed for frequency and compared according to age group, sex, geographical location and length of 
service. Open-ended question responses were analysed to identify common issues and themes.

\section{Results}

VAO closely resemble other Australian volunteers ${ }^{10}$ in age and sex (55\% female); however more VAO are employed (83\% versus 44-58\%), and fewer have completed tertiary study. Most respondents had been VAO for five years or less (Figure 1), with exit rates increasing after two and a half years.

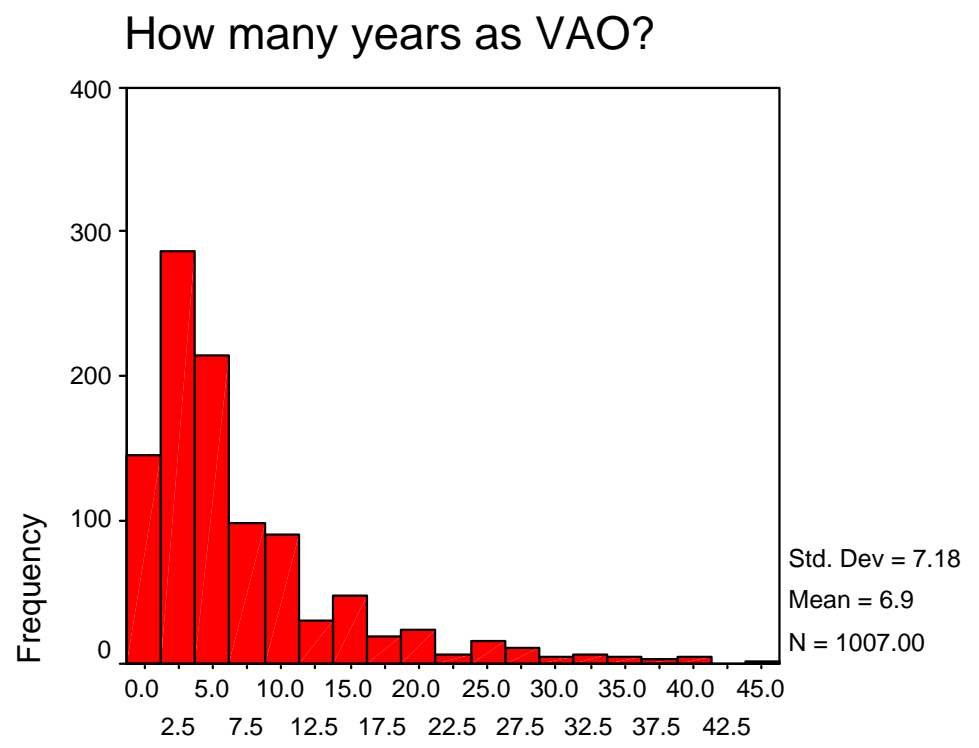

How many years as VAO?

Figure 1: Years respondents had been VAO

Important motivations for VAO (those rated as above average or very important) are assisting the community (93\%), gaining new skills (87\%), and gaining a sense of achievement (86\%), plus over $50 \%$ reported various social benefits. For many, an interest in the medical and first aid field was the motivator that attracted them to the ambulance service instead of other volunteer roles (Table 1). VAO activities that were listed as enjoyable were coded with three main categories identified: training and skills maintenance; helping people; and group friendships. The major factors that made volunteering difficult were lack of time (33\%) and inadequate provision of resources (29\%). 
Table 1: Respondents motivations for becoming a Volunteer Ambulance Officer.

\begin{tabular}{lcccccc}
\hline \hline & Not at all & Not & Average & Above & Very & Total \\
\cline { 2 - 7 } & $\%$ & $\%$ & $\%$ & $\%$ & $\%$ & Frequency \\
\hline $\begin{array}{l}\text { The local ambulance group } \\
\text { stood out in the community }\end{array}$ & 22.4 & 21.5 & 28.9 & 14.6 & 12.6 & 915 \\
$\begin{array}{l}\text { I has seen the VAO in action } \\
\text { and it prompted me to join }\end{array}$ & 45.0 & 20.6 & 18.1 & 7.8 & 8.4 & 916 \\
$\begin{array}{l}\text { I had friends or family who } \\
\text { were members }\end{array}$ & 54.4 & 10.7 & 10.8 & 10.1 & 13.7 & 917 \\
$\begin{array}{l}\text { A representative of the } \\
\text { organisation asked me to join }\end{array}$ & 46.8 & 7.7 & 9.2 & 13.6 & 22.5 & 927 \\
$\begin{array}{l}\text { The organisation advertised } \\
\text { for volunteers }\end{array}$ & 44.8 & 10.5 & 13.1 & 11.9 & 19.6 & 908 \\
$\begin{array}{l}\text { The station needed more } \\
\text { volunteers to continue }\end{array}$ & 25.3 & 8.1 & 12.3 & 17.2 & 36.9 & 935 \\
$\begin{array}{l}\text { I am interested in the } \\
\text { medical/first-aid field }\end{array}$ & 2.8 & 4.2 & 12.9 & 19.7 & 60.2 & 989 \\
\hline \hline
\end{tabular}

Most respondents (77\%) attended training weekly or fortnightly, depending on the jurisdiction. Respondents wanted either more training or the same amount, with $57 \%$ wanting more formal training with qualified trainers. A comparison between frequency of training and desire for more formal training showed that most of those with low frequency of training wished for more, but also that nearly half of those who often had formal training wished for more (Figure 2). Only a few individuals wished for less formal training.

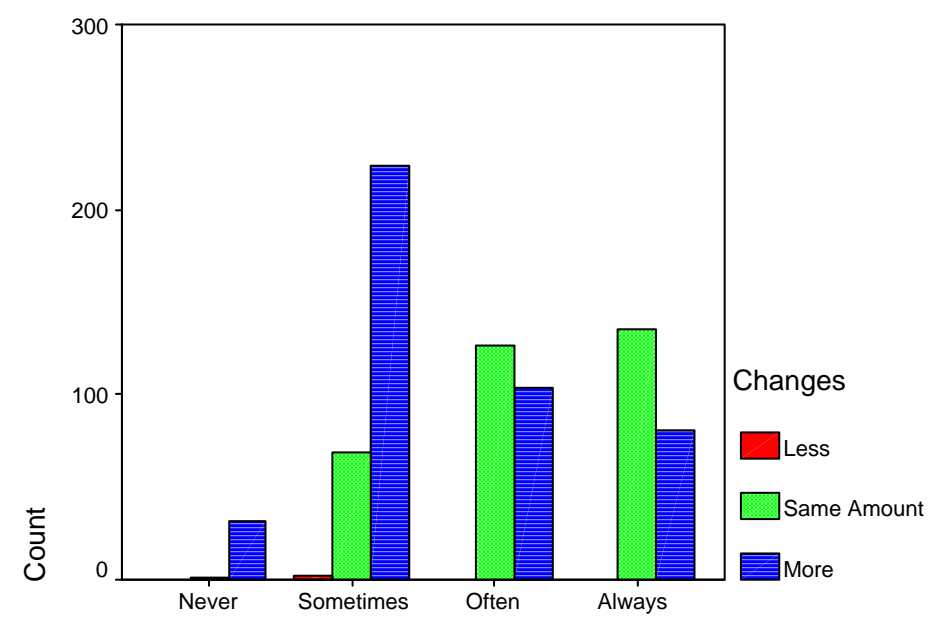

Currently training with a qualified trainer

Changes $=$ desired frequency changes to training with qualified trainer 
Figure 2: Desired training changes by current training level.

Many respondents felt that training was often (37\%), or always (33\%) appropriate for their needs. Seventy-three per cent found training sessions often or always interesting and $83 \%$ agreed that training sessions often or always had the necessary equipment. Delivery of training by electronic methods was under-utilised by training providers, with $53 \%$ of respondents never, and $21 \%$ sometimes having access to training materials on the Internet. Similarly $82 \%$ never, and $11 \%$ sometimes had videoconferencing or teleconferencing training sessions.

Thematic analysis of the qualitative data showed many comments were based on training issues or suggestions for improvement. Themes around the expectations of training standards, assessments and reaccreditations were polarised. For example:

Too much emphasis on reassessment has led to resignations especially as assessed by different people and no consistency in requirements. Training and assessment should have national standards, and active duty needs to be taken into consideration as part of assessment.

Higher qualifications for volunteers who wish to advance further to provide community with same level of service as city.

Training standards and technology at standard of amateur doctor difficult to absorb on a part-time basis.

Desperately need access to tertiary courses, which are denied as not full time ambo - tertiary courses would still be in own time and at own expense.

Management at training level have become dictatorial and this attitude will cause volunteers to leave the service. The service now expects volunteers to train to intermediate level but not all volunteers want that much commitment.

Another major theme emerging around training was that many VAO felt training should be more flexible. For example:

Training needs to have set outcomes, with the steps on the way and practical /theoretical scenarios to complement it.

Difficult for country vollies to get to city for courses.

Suggest quality training through Satellite Network - sites at every town where there is a hospital. 
Formal training structure so don't have to rely on the unit, e.g. internet, CD-Rom, video, teleconference, videoconferencing.

Training is a big issue for me. What is offered at local station level is catering for induction level. My skills and competency are never checked, but I am the highest qualified on all my shifts. This for me is an issue - one of safety. Something needs to be put in place for annual reassessments. Further formal training would take all my annual leave for the next two years, and is for me unjustifiable. However, if this training were offered at nights and weekends, with videoconferencing it would be achievable.

Another theme was the approach to new recruits. Services with high training requirements had a strong theme of losing new recruits through the length of time taken for recruits to become active, and the high training as a disincentive to join. Services with less frequent training had comments about losing recruits as they waited too long to receive training. For example:

We have a serious shortage of volunteers and it takes typically 8-12 months for a new recruit to become trained. Almost $1 / 3$ of our volunteers are now 'observers'.

Work is rewarding and valuable, however high expectations of new volunteers may be off-putting.

Currently training to be an ambulance officer, enjoying every minute. Look forward to becoming accredited soon.

\section{Discussion}

The Stand Up and Be Counted Project provides ambulance services with timely information about ambulance volunteer's training and support needs as they move towards incorporating the Health Training Package Qualifications (HTPQ) under the National Training Framework. As the research identifies that training is very important to recruiting and retaining $\mathrm{VAO}$, it can be considered an important motivation if done well, or conversely a demotivator if poorly provided. Training forms an important link in the efforts of VAO to help the community, as well as an important form of reciprocation from ambulance services to VAO. The research highlight that training could be more flexible to meet the needs of VAO, and that VAO want consistent standards. Within a framework of consistent standards and quality delivery, some VAO want to achieve high levels of formal ambulance officer qualification, and others do not.

The polarization of comments could be considered to have three causes: different training systems per jurisdiction; some units were better serviced than others due to isolation and regionalisation factors; and individuals had different expectations and capacities. Services that offer the least training, and limited the level a VAO could aspire to, had comments from individuals 
wishing to obtain higher standards. Services with high training requirements had comments from individuals who felt the expectations were too high, but also had some comments from those who wanted more training.

Assessment and reaccreditation comments also showed this polarization. It is obvious that VAO want consistent standards and assessment, but some want higher standards than others. Comments also showed that some methods of assessment and reaccreditation were viewed as high-handed and offensive. This is important information for services hoping to introduce the HTPQ. The Australian Quality Training Framework over the last decade has formed a basis for reinventing Australia's vocational and educational training system into one that is more competencies based and nationally recognised ${ }^{11}$. The HTPQ would provide a Certificate III in Non-Emergency Patient Transport (395 hrs) and a Certificate IV in Basic Emergency Care (780hrs), and will align closely with qualifications already offered by some jurisdictions. The benefits for volunteers will be the provision of quality standardised training, and the awarding of nationally recognised qualifications. The difficulties may lie in the extra commitment required to complete the courses.

Ensuring volunteers have reached a certain level of competency is part of the duty of care ${ }^{3}$, and this is an important motivation for the uptake of the new training packages. Training must perform three functions: assisting VAO to gain new skills; assessing that VAO are competent; and assisting VAO to maintain skills ${ }^{11}$. Gaining and maintaining skills requires assessment, and our research shows VAO understand the importance of assessment. However, inflexible application of assessment requirements is unappreciated by VAO, and can be perceived as an imposition. Therefore with increases in training and accreditation requirements management must adopt flexible and encouraging programs to assist VAO to meet their obligations. Onerous and dictatorial approaches should be avoided to prevent training and reassessment requirements becoming a deterrent to volunteers.

Providing appropriate training, equipment and support for VAO requires a substantial financial investment for ambulance services, but one that acknowledges the important role VAO play in rural and regional Australia and New Zealand. It is important to provide interesting and varied training that is held at suitable times and locations as this acknowledges that VAO time is a valuable resource. It is management's role to ensure training is adequately resourced, presentation is appropriate and varied, and sessions are accessible ${ }^{4}$. On the whole, many volunteers felt these factors were present in training sessions, but there is clearly scope for increasing the use of the internet, videoconferencing and teleconferencing to increase the flexibility of delivery. The reasons for under-utilisation of electronic training methods are not well understood, and may need further investigation, though possibly financial constraints play a large role. However, the particularly strong benefits for the more isolated groups who suffer most from lack of nearby back up may provide budget justification, and the potential for states to share electronic training material and therefore costs is an added motivation. 
Prompt orientation programs and mentoring for the first year are successful strategies for retention of new volunteers ${ }^{4}$. VAO signalled that high training expectations of new recruits (for some services) are a factor in the high turnover, as is leaving recruits as 'observers' for extended periods (either because of high training requirements or lack of training opportunities). Both of these were believed to lead to a rapid loss of motivation. New volunteers respond to an early induction and training that allow them to participate in activities. With many VAO indicating that rosters are inadequately covered and that time pressure is one of their major difficulties, prompt induction may benefit all.

High volunteer turnover may mean ambulance services are wary of investing too many resources in VAO training. But appropriate training provision is part of the organisations 'duty of care' to the volunteers and the public and is likely to be management's most powerful recruitment and retention tool. Training ensures emergency service volunteers are competent and confident. With tight resources services may not adequately resource the new HTPQ causing VAO to feel unsupported and stressed. Services must acknowledge that the benefits of providing timely, consistent, quality training will outweigh the actual financial cost. The risks of providing inconsistent and poorly resourced training are high volunteer turnovers, limited skills and dwindling emergency capacity. Ambulance services aiming to recruit and retain volunteers should investigate the flexibility, quality and timeliness of the training they deliver to ensure it reinforces the motivations of their workforce. These issues will require monitoring for services introducing HTPQ, as onerous demands on volunteer's time without adequate support will increase retention difficulties.

\section{Conclusion}

The role of VAO in health and emergency services is important because of the numbers reliant on this service, and the health profile of the rural population. The utility of training to VAO is an important finding as ambulance services are experiencing difficulties with recruiting and retaining volunteers. Ambulance services must not be afraid that training standards are a deterrent to potential volunteers. It is clear that appropriate training will act as a powerful recruitment and retention tool for VAO if provided in a timely and suitable manner. But poorly delivered or inflexible training will be a disincentive to VAO and will be counterproductive. Ambulance services must keep these factors in mind while introducing the new HTPQ, and closely monitor their impact on VAO. 


\section{References}

1. Bryant DL, Strasser PR. The delivery of sustainable rural and remote health services: Regional Australia Summit Unit, 1999 [cited 2002 May 8]. Available fromURL:

http://www.dotrs.gov.au/regional/summit/program/background/bryant strasser .htm.

2. Howard B. Managing Volunteers. Australian Journal of Emergency Management 1999; 14:37-38.

3. Aitken A. 'Identifying key issues affecting the retention of emergency service volunteers.'. Australian Journal of Emergency Management 1999;14:16-24.

4. Federal Emergency Management Agency. Emergency Medical Services Recruitment and Retention Manual: Federal Emergency Management Agency; 1995.

5. Hudgings E. Volunteer incentives; Solving recruitment and attrition problems. Journal of Emergency Medical Services 1988; 13:58-61.

6. Reinholdt S, Smith P. Directions in Volunteer Development in Australian Emergency Services. Mt Waverly: Country Fire Authority and Emergency Management Australia; 1998.

7. Swan T. Training to win. Emergency 1991; 20:41.

8. Fahey C, Walker J. Emergency Services in Australia and New Zealand: Problems and Prospects for Volunteer Ambulance Officers. Hobart: University of Tasmania, 2002; 1 - 70.

9. Fahey C, Walker J, Sleigh A. Training can be a recruitment and retention tool for emergency service volunteers. The Australian Journal of Emergency Management 2002;17(3):3-7.

10. Australian Bureau of Statistics. Voluntary Work, [online report], 2001; [cited 2002 Apr 11]; Available from: URL: www.abs.gov.au/ausstats/abs@.nsf/Lookup/NT0001AA0E

11. Stone R. Training for a Safer Community: Volunteer Development within the Australian Quality Training Framework. Paper presented to the Value Your Volunteers or Lose Them - A Summit; 2001 Oct 11-12; Canberra, Emergency Management Australia. 